\title{
31
}

\section{Thermal Enrichment by Stormwater: Review for the Development of a Suitable Model}

\author{
Yi Li and William James
}

This chapter discusses studies on the thermal enrichment of receiving water bodies due to urban runoff, and the development of a general model to compute runoff temperature at a fine time step and spatial resolution. Complex urban drainage systems comprise many different elements; the model proposed herein is applicable to many of these, and may be configured for large systems.

\subsection{Introduction}

It is a truism to say that rapid urbanization, while bringing development and prosperity, has negative environmental impacts. An example is thermal enrichment of receiving water bodies due to urban stormwater. This source of thermal pollution has been neglected, compared with industrial thermal discharges, but is increasingly being recognized as a potential threat to the aquatic environment.

Urbanization typically reduces the original vegetal cover and introduces impervious surfaces. By its excellent mulching and infiltration capability, the original vegetated watershed (e.g. old-growth forest) allowed groundwater recharge, whereas artificial surfaces, such as roads and parking lots, are generally impervious and do not recharge groundwater to the same extent, reducing base flow and causing greater runoff rates and pollutant fluxes. Thus urbanization increases erosion, direct inflow and pollution to receiving water bodies.

Li, Y. and W. James. 2004. "Thermal Enrichment by Stormwater: Review for the Development of a Suitable Model." Journal of Water Management Modeling R220-31. doi: 10.14796/JWMM.R220-31. (C) CHI 2004 www.chijournal.org ISSN: 2292-6062 (Formerly in Innovative Modeling of Urban Water Systems. ISBN: 0-9683681-9-0) 
Thermal enrichment due to urbanization arises from two sources:

1. Surface area of open water, such as ponds and streams, is increased. Open water receives more insolation; in summer time, insolation often is the primary heat source to an open water body.

2. Artificial impervious surfaces in urban areas, constructed from materials such as concrete and asphalt, absorb more heat from insolation than do natural surfaces (Beard and Johns, 1985). When runoff occurs (now increased in volume), the surfaces heat the runoff. The heated, increased, runoff water is efficiently delivered into the downstream receiving water body through the drainage system, often directly.

Although water temperature is not normally explicitlyincluded in stormwater quality indexes (Moffa, 1996) it is appearing in municipal stormwater management ordinances across North America, especially in areas with coldwater communities. More and more municipalities are beginning to recognize and manage the thermal enrichment problem (City of Fitchburg, 2003; Dane County, 2002).

Water temperature is an important water quality index in an aquatic environment. It influences at least three principal facets: (i) the aquatic ecosystem; (ii) biological and chemical reactions; and (iii) physical properties of water, such as density (Thomann and Mueller, 1987). Long-term thermal pollution, as measured for example by increasing mean seasonal water temperature, is harmful to a water environment. From an ecological point of view, even a moderate increase in temperature changes the species of fish and wildlife. For example, salmon and trout thrive in cold water, being unable to reproduce in an environment even a few degrees warmer (Heathcote, 1998).

Thermal research on urban stormwater is still at an early stage, lacking theoretical and experimental support, especially for low or shallow flow. In addition, a large number of variables are involved, causing many uncertainties. Thus thermal modeling is not widely used, and our research is intended to develop a practical, comprehensive thermal enrichment model for direct runoff temperature simulation in an urban watershed.

\subsection{Previous Work}

Many previous studies have been published on the processes and impacts of thermal enrichment due to urban runoff. Basically, there are two major research approaches: macroscopic and microscopic. 


\subsubsection{Macroscopic Approach}

This approach focuses on relationships such as those between imperviousness and stream temperature, air temperature and stream temperature, and air temperature and runoff temperature. A number of practical studies and experiments have provided empirical equations based on statistical analyses and qualitative information.

After research on five streams in Long Island, New York, Pluhowski (1970) concluded that, in the past several decades, the rapid increase in urban population intensity has most affected stream ecosystems and environments. He found that changes resulting from human activities enhanced average stream temperatures by $5^{\circ} \mathrm{C}$ to $8^{\circ} \mathrm{C}$ during summer. During high solar radiation days, stream temperature in changed areas was recorded to be $8^{\circ} \mathrm{C}$ to $10^{\circ} \mathrm{C}$ higher than in undisturbed streams. For certain meteorological conditions, storm water flowing into receiving channels from urban areas may significantly change the stream temperature. An obvious case occurred in Nassau County and southwestern Suffolk County, where on August 25 and 26, 1967, a large number of runoff events enhanced the water temperature by $5.5^{\circ} \mathrm{C}$ at one site and $8.5^{\circ} \mathrm{C}$ at another. As the direct runoff receded, the previous stream temperature pattern recovered. The main causes of these temperature changes were thought to be associated with urbanization activities such as removal of vegetation, and increased impervious surfaces, which in turn caused more direct stormwater runoff, and less groundwater exfiltration.

Xie (Xie and James, 1993; James and Xie, 1994) investigated storm water thermal enrichment in the Speed River at Guelph, Ontario, using the Hydrological Simulation Program-FORTRAN (HSPF). Her study found out a linear relationship between stream temperature Ts and percentage imperviousness I:

$$
T s=17.0+0.011
$$

where:

$$
\begin{aligned}
T_{S}= & \text { computed mean water temperature of stream } \\
& \text { (May } \sim \text { Sept.) }\left({ }^{\circ} \mathrm{C}\right), \text { and } \\
I= & \text { watershed imperviousness }(\%) .
\end{aligned}
$$

This relationship is similar to that derived by Galli (1990), based on a study of water temperature monitoring in the Anacostia River basin, Maryland. Galli developed an equation for a headwater Piedmont stream: 


$$
T s=15.8+0.076 I
$$

where:

$$
\begin{aligned}
T_{S}= & \text { mean water temperature of stream (late-spring/sum- } \\
& \text { mer) }{ }^{\circ} \mathrm{C}, \text { and } \\
I= & \text { watershed imperviousness }(\%) .
\end{aligned}
$$

Despite the difference between coefficients due to different watershed characteristics, Equations 31.1 and 31.2 show a similar relationship between temperature and the urban impervious area. Clearly, imperviousness, which results from urbanization, will result in an increase in stream water temperature.

In addition, Xie performed three experiments to derive an empirical equation to calculate the expected mean temperature of surface runoff over paving:

where:

$$
T_{R}=3.26+0.828 T_{P W}
$$

$$
\begin{aligned}
T_{R}= & \text { expected mean temperature of surface } \operatorname{runoff}\left({ }^{\circ} \mathrm{C}\right), \\
& \text { and } \\
T_{P W} & =\text { temperature of wet pavement }\left({ }^{\circ} \mathrm{C}\right) .
\end{aligned}
$$

This tentative expression was an attempt to establish a relationship between pavement temperature and runoff temperature.

\subsubsection{Microscopic Approach}

Whereas numerous macroscopic analyses have provided a clear idea of the thermal effects of urban runoff, more effort is needed to reveal the inner mechanisms of this thermal effect. Unlike the macroscopic approach, microscopic studies focus on the intrinsic physical processes of urban thermal enrichment. Estimation of water temperature variation under various meteorological conditions is the primary target, particularly, the heat transfer mechanism in overland runoff, and the major source of urban stormwater.

In this work, the energy balance method is applied. The usual energy balance covers a few principal heat transfer components for an open water body: convection, rainfall mixing, evaporation (sensible heat), and radiation as shown in Figure 31.1. For overland runoff, there are two essential thermal processes: heat mixing in runoff water, and conduction in the underlying material under the water.

Four previous studies are available for review. 


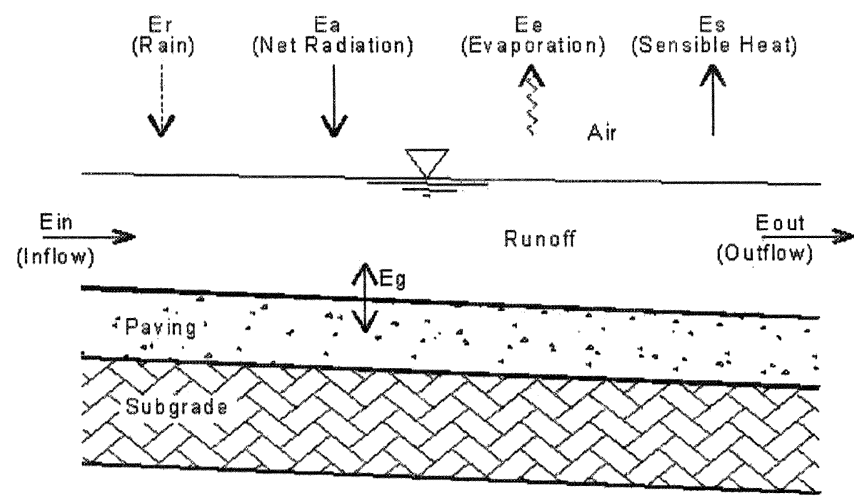

Figure 31.1 General sketch of energy budget for overland runoff. where: $\quad \mathrm{Er}=$ energy introduced by rain;

$\mathrm{Ea}=$ net radiation;

$\mathrm{Ee}=$ energy loss by evaporation;

Es = energy loss by sensible heat flux;

Ein = energy introduced by inflow;

Eout $=$ energy loss by outflow; and

$\mathrm{Eg}=$ convection transfer between water and ground.

Verspagen Study

In a laboratory study, James and Verspagen (1996) examined the thermal enrichment of surface runoff by monitoring the change in temperature between the simulated rainfall at the inlet and the surface runoff at the outlet from two sample pavements each measuring $1 \times 1 \times 0.5 \mathrm{~m}$ :

1. with an impervious asphalt surface, and

2. with a concrete permeable paver stone known as Eco-Stone, supplied by Unilock Canada Inc.

Results indicated that both paving surfaces under insolation can cause an increase in the temperature of surface runoff. They produced an empirical relationship for the temperature change. The relationship involved rainfall intensity, thermal conductivity of the surface, and the initial runoff and rainfall temperatures.

Verspagen (James and Verspagen, 1996) also proposed a theoretical method to estimate the temperature of surface runoff. After calculating various heat transfer components, the final runoff temperature is given by:

$$
T_{s r}^{\prime}=\frac{q_{r} T_{r}+q_{s r} T_{s r}}{q_{r}+q_{s r}}
$$


where:

$T_{s r}{ }^{\prime}=$ mean temperature of the film of water on the paving surface evaluated for the current time step $\left({ }^{\circ} \mathrm{C}\right)$

$T_{r}$ and $T_{s r}=$ temperatures of rainfall and surface runoff from the previous time step $\left({ }^{\circ} \mathrm{C}\right)$

$q_{r}$ and $q_{s r}=$ rainfall flow rate and surface runoff flow rate $\left(\mathrm{m}^{3} / \mathrm{s}\right)$.

For the key average convection heat transfer coefficient $\bar{h}\left(\mathrm{w} / \mathrm{m}^{2} /{ }^{\circ} \mathrm{C}\right) \quad$ Verspagen suggested standard empirical equations for turbulent flow based on Schlichting's boundary layer theory (Holman, 1986). The combined form of the equations is:

$$
\bar{h}=\operatorname{Pr}^{\frac{1}{3}}\left(0.037 \operatorname{Re}_{L}^{0.8}-850\right) \times \frac{k}{L}
$$

where:

$$
\begin{aligned}
k & =\text { thermal conductivity of the overlying fluid }\left(\mathrm{w} / \mathrm{m} /{ }^{\circ} \mathrm{C}\right) \\
L & =\text { length of water flow over the paving surface }(\mathrm{m}), \\
\operatorname{Pr} & =\text { Prandtl Number of fluid, and } \\
R e_{L} & =\text { length-based Reynolds Number. }
\end{aligned}
$$

The proposal attempts to reveal the mechanism of stormwater runoff thermal enrichment, making many reasonable assumptions. However, equation (4) did not consider heat fluxes by radiation, evaporation and convection, and from the viewpoint of the energy balance, is incomplete.

In addition, Equation 31.5 is empirical, determined from the results of experiments on uniform flow over a flat plate that has a leading point. The experiments were based on boundary layer theory, with the restriction that the plate surface temperature remains constant.

In practical implementations, direct application of Equation 31.5 will encounter some difficulties:

1. real pavement surfaces have no "leading point";

2. runoff is unsteady, and therefore non-uniform;

3. paved surfaces are rough and randomly sloping; and

4. the temperature of the pavement surface varies during a rainfall event.

Nevertheless Verspagen's study started a new research thrust in the thermal enrichment of stormwater runoff. 


\section{TRMPAVE}

Buren (1999) studied two thermal processes: (i) a parking lot (size: $45 \mathrm{~m} \times 2 \mathrm{~m}$ ), and (ii) a receiving pond for the parking lot. A large quantity of field data was collected for both parts.

The purpose of the pavement experiment was to develop a heat transfer model for computing the thermal enhancement of stormwater over a paving surface. TRMPAVE was designed to determine the temperature gradient in the pavement. Runoff temperature was simply assumed to be the average of the rainfall and ground surface temperatures, while the calculation concentrated on the paving.

Beneath the paving surface, the heat transfer was assumed to follow an unsteady conduction formulation, which is reasonable. A finite difference method was used to obtain numerical solutions for the unsteady conduction.

At the interface between the paving surface and runoff or air, a boundary condition was applied to solve the unsteady conduction equation. For example, the boundary condition during wet-weather periods was:

where:

$$
\left.\frac{\partial T}{\partial y}\right|_{y=0}=\frac{h}{k}\left(T_{s}-T_{\infty}\right)-\frac{q_{\text {rad }}}{K}+\frac{q_{\text {evap }}}{K}
$$

$$
\begin{aligned}
T= & \text { temperature(function) of paving }\left({ }^{\circ} \mathrm{C}\right), \\
y= & \text { depth from the paving surface }(\mathrm{m}), \\
T s= & \text { surface temperature of paving }\left({ }^{\circ} \mathrm{C}\right), \\
T \infty= & \text { air or runoff temperature }\left({ }^{\circ} \mathrm{C}\right), \\
k= & \text { thermal conductivity of paving material }\left(\mathrm{w} / \mathrm{m} /{ }^{\circ} \mathrm{C}\right), \\
h= & \text { heat transfer coefficient between paving and air or } \\
& \text { runoff }\left(\mathrm{w} / \mathrm{m} 2 /{ }^{\circ} \mathrm{C}\right), \\
q_{\text {rad }}= & \text { net radiation on paving surface }\left(\mathrm{w} / \mathrm{m}^{2}\right), \text { and } \\
q_{\text {evap }}= & \text { heat transfer due to evaporation }\left(\mathrm{w} / \mathrm{m}^{2}\right), \text { including } \\
& \text { sensible heat flux. }
\end{aligned}
$$

The model worked well for the surface temperature of paving, with the aid of various measured meteorological parameters, such as net solar radiation, air temperature, wind speed, relative humidity, barometric pressure, etc.

For the pond analysis, the water temperature of the pond was estimated using a regular energy budget method. The heat transfer component included inflow into the pond, outflow from the pond, net solar radiation, and evaporation (including sensible heat). The first three items were obtained from field data, while the last was calculated using observed meteorological data. 
Results for the two parts indicated that the thermal energy influx from the parking lot accounted for $23 \%$ of the total input to the receiving pond during wet-weather periods, even though the parking lot area is only $0.3 \%$ of the total catchment area. This finding, again, proved the potential for thermal enrichment of urban storm runoff. The study demonstrated the applicability of the heat budget approach to some extent, especially the pond component.

However, heat flux from rainfall was not carefully considered by either of the two models, though rainfall was introduced to get runoff temperature in paving modeling, i.e. runoff temperature was assumed to be the average of the rainfall and ground surface temperatures. A problem is that rainfall was not considered in the total mass balance. Thus this treatment may not realistically depict the effect of rainfall. The first model produced a relatively better result for the study site $(45 \mathrm{~m} \times 2 \mathrm{~m})$, but scaled-up results over-estimated total thermal energy measured at the outfall sewer for the whole parking lot (total area: 12.6 ha) by $49 \%$. In fact, total thermal energy calculated at the outfall was $2.59 \times 1011 \mathrm{~J}$ based on the observed discharge and temperature, while the scaled-up value was $3.87 \times 10^{11} \mathrm{~J}$ calculated from the test plot area. The incomplete cooling effect of the relatively cooler rainfall water may be a major cause for this overestimation, though the difference was partially attributed to the discrepancy in measured and simulated runoff volumes $(21 \%)$ by the original author.

Probably Equation 31.6 should also be re-considered. At the boundaries of a control volume, i.e. the paving in this case, in general, the boundary condition only need consider elements adjacent to the control volume. However, Equation 31.6 considered not only runoff from an adjacent element, but also solar radiation on the surface. Sunshine can perpetrate water to some extent, but the assumption of complete perpetration ignores the heat absorbed by the water, and the albedo of the rough water surface, even when the overland sheet flow is very shallow.

As for the convective heat transfer coefficient hc, the paving model adopted an existing empirical equation during dry-weather periods. During wet period, hc was expressed:

$$
h c=3.46 \cdot i^{1.1}
$$

where:

$$
i=\operatorname{rainfall} \text { intensity }(\mathrm{mm} / \mathrm{h}) \text {. }
$$

This statistical relation may apply when rain is falling, but is inapplicable when rainfall ceases. 
Possibly the most important assumption is that the temperature of runoff is the average of rainfall temperature and surface temperature of the paving. In other words runoff temperature is assumed to be a known input parameter in their model calculation, whereas computation of runoff temperature is one of core targets in the present thermal enrichment research. Buren focused on the computation of the temperature of the paving surface, rather than runoff temperature.

\section{TES}

Haq (Haq and James, 2002) developed a model TES to estimate stormwater thermal enrichment for a project in Portage Creek, Michigan. Written in Microsoft Excel, TES is a direct application of Verspagen's work (op cit) to calculate water temperature at the outlet of runoff drainage system for a given watershed, with flow rates provided by PCSWMM.

Three major heat transfer components are incorporated into TES: (i) rainfall, (ii) convection between runoff and ground, and (iii) evaporation. In fact, the effect of convection and evaporation is directly embedded into Tsr in the heat balance equation (Equation 31.4). Another important heat transfer component, radiation, is assumed to be equal to sensible heat. Thus they eliminated each other.

When a rainfall event was simulated, it did not produce the expected effects: runoff temperature kept increasing, but the temperature of the paving surface did not decrease as heat was transferred to runoff. The incomplete heat balance, Equation 31.4, and the limited applicability of Equation 31.5, may be the main cause of the poor result.

In TES a big change was made in the calculation of the Reynolds Number $\operatorname{Re}_{\mathrm{L}}$. In Equation 31.5, $\mathrm{Re}_{\mathrm{L}}$ was originally length-based. In TES, the number was calculated based on the runoff depth. For this reason, as Haq(2001) stated "...the length of flow used for hydraulic calculations produces a very high Reynolds Number and as a result TES estimated almost hundred deg-C temperature changes within a 5-min time step." It also indicates that Equation 31.5 is hard to apply at a large scale.

On the other hand, the watershed was highly simplified. Except for the main drainage channels and subcatchments, pipes and ponds within the watershed were ignored. All heat transfers took place only on the paving surface, meaning the whole watershed was treated as one large block of paved land. Therefore, all mixing processes were missing. The temperature change inside the pavement was also highly simplified, being assumed to be linear. 
In spite of the imperfect result, TES was an excellent attempt to directly compute runoff temperature. It was also the first effort to link PCSWMM to stormwater thermal enrichment.

\section{TURM}

A further model, the Temperature Urban Runoff Model (TURM), was used in Dane County, Wisconsin. The model was developed to estimate post-development runoff temperature. The model is still under development, so only a rough description is presented here.

Unlike TRMPAVE and TES, which continuously simulate a rainfall event to compute changes as a function of time, TURM computes just one temperature for a rain event, ignoring continuous changes of temperature and meteorological conditions during the event. TRMPAVE and TES may be considered time-distributed, whereas TURM might be considered time-lumped.

TURM uses mean meteorological data such as: wind speed, relative humidity, initial temperature of the impervious surface, and air and rain temperatures. It does not account for the inherit variability of rainfall due to changes in intensity and the type of storm, as it assumes that rainfall is uniform over the duration of the event. Hence, for rainfall, only depth, duration, and time of onset are needed for input (Roa and Norman, 2002; Roa-Espinosa et al., 2002; Roa-Espinosa et al., 2003)

Runoff is treated as sheet flow, or more precisely as kinematic-wave flow, in the model. The fundamental approach is to compute mean water temperature at the exit of an impervious surface by integrating all energy exchanges associated with the sheet flow over the length of land slope. (Roa and Norman, 2002). A special equation is used to calculate water temperature. The model divides runoff into three flow types: (i) sheet, (ii) shallow concentrated, and (iii) open channel, thus obtaining a time of concentration. Physical constants considered in the equation include: (i) heat capacities and (ii) thermal conductivities of (iii) water and (iv) pavement, (v) latent heat of water, (vi) density of water, (vii). dynamic viscosity of water, (viii) atmospheric pressure, and (ix) the universal gas constant (Roa and Norman, 2002).

Because of the absence of radiation, a crucial component in the heat budget for open water, the model treats incident solar radiation as a sine wave over the day. The sine wave approximation can be extended to air temperature and surface temperature (Barber, 1957), independent of real meteorological conditions. Norman and Roa (2000) suggest that the sine wave be used for estimating pavement temperature during dry periods. 
The advantage of TURM is its convenience of use, using only constants, and a highly simplified representation of the watershed, as in TES. As all thermal processes are assumed to take place on the paving surface (single application assumption), the model's interface is very concise (Roa et al., 2003). Like TES, TURM ignores all mixing processes in the watershed, due to the single application assumption. For complex watersheds, some mixing processes, for example in the sewer network, may be essential to correctly estimate water temperature in receiving water bodies. Furthermore, heat transfer mechanisms for different mixing processes could be very different.

The assumption of constant meteorological conditions may be effective for short rain events. In longer, intermittent events, or for continuous hydrology, however, meteorological conditions can vary over a wide range. TURM is not applicable to such conditions.

Though convection is considered, conduction in pavement seems to be ignored. Conduction will certainly affect convection. In turn, convection influences runoff temperature.

One finding in the final TURM report (Roa and Norman, 2000) is encouraging for rainfall temperature estimates: air temperature is a good approximation to rain temperature for events prior to noon.

\section{Ontario Studies on Stream Temperatures}

For stream temperature evaluation, Weatherbe (1995) employed a simplified energy balance method that ignores several heat sources and sinks. Creek temperature was calculated as a one-dimensional spatial variable based on equilibrium temperature, so that a longitudinal temperature profile can be obtained. The determination of equilibrium temperature was extremely empirical. All flow and temperature inputs at the upstream end of a channel, such as from runoff, base flow and channel self, were treated as constants. Without calibration, Weatherbe regarded this method as a screening tool.

Schroeter et al. (1995) applied GAWSER to estimate creek temperature, based on a complete mixing condition. Equilibrium temperature was also used as a parameter. Runoff temperature was approximated as the average of ground surface and precipitation temperatures. Sensitivity analysis showed that ground surface temperature greatly influenced the results.

Both studies focus on stream, assuming that overland runoff temperature is known a priori. 


\subsection{Conclusions}

The following points summarize previous work and form a basis for our model development:

1. The serious impact of thermal enrichment of urban stormwater on receiving waters is repeatedly verified by much research.

2. The direct computation of runoff temperature should be a target of current research. Complete modeling at a watershed level should permit computation of water temperature at various locations. In other words, heat transfer should be separately computed for sheet flow, pipe flow and channel flow. A distributed, temperature model framework could become a development trend, much like distributed hydrological modeling.

3. The heat budget method should be the basis of this research. A relatively complete and clear energy balance is necessary not only for ponds and sewers, but also for overland flow. It should be noted that mass balance is also key.

4. Thermal processes internal to the paving should be given more attention. The process is non-linear, but influences heat flux across the ground surface.

5. For the convective heat transfer coefficient $h$ between surface runoff and the paving surface, an applicable equation is required. A field experiment will help to determine it. Without experimental support, however, a dimensional analysis may lead to an appropriate equation. Probably the coefficient will be case dependent.

6. Appropriate assumptions, approximations and simplifications will be absolutely indispensable. Thermal research on stormwater is basically still at an early stage, lacking theoretical and experimental support, especially the thermal behavior of low or shallow flow. In addition, a large number of variables are involved, causing many uncertainties.

\section{References}

Barber, E.S. (1957) Calculation of maximum pavement temperature from weather reports. Bulletin 168. Highway Research Board, Washington, D.C. pp: 1-8.

Beard, J.B. and Johns, D. (1985) The comparative heat dissipation from three typical urban surfaces: asphalt, concrete, and a Bermuda grass turf. In: Texas Turfgrass 
Research. Texas Agricultural Experiment Station. PR-4329. College Station, TX. pp: 125-133.

Buren, M.A.V. (1999) Thermal enhancement of urban receiving waters. PhD dissertation, Department of Civil Engineering, Queen's University, Kingston, Ontario. 199 pages.

City of Fitchburg, Wisconsin. Accessed March 2003. Erosion Control and Stormwater Management Ordinance. (adopted August 13, 2002). <http:// www.city.fitchburg.wi.us/Stormwater/CH27.pdf $>$.

Dane County, Wisconsin. Accessed August 22, 2002. Erosion Control and Stormwater Management Ordinance. <http://www.co.dane.wi.us/commissions/lakes/doc/ summaryaug2002.doc>

Galli, J. (1990) Thermal Impacts Associated with Urbanization and Stormwater Management Best Management Practices. Metropolitan Washington Council of Governments, Washington, D.C. pp. 157.

Haq, Rizwan and James, William, 2002. Modeling urban runoff temperature. Presented at Conf. on Urban Water Systems, Toronto, ON. Feb.21-22, 2002

Heathcote, I.W. (1998) Integrated Watershed Management. John Wiley \& Sons, Inc. pp: 41.

Holman, J.P. (1986) Heat Transfer. McGraw Hill, Toronto. 676 pages.

James, W. and B. Verspagen. 1996. "Thermal Enrichment of Stormwater by Urban Pavement." Journal of Water Management Modeling R195-08. doi: 10.14796/JWMM.R195-08.

James, W. and J. Xie. 1999. "Modeling Thermal Enrichment of Streams due to Solar Heating of Local Urban Stormwater." Journal of Water Management Modeling R204-08. doi: 10.14796/JWMM.R204-08.

Moffa, P.E. (1996) The Control and Treatment of Industrial and Municipal Stormwater. Van Nostrand Reinhold. pp: 121-129.

Norman J.M. and Roa, A. (2000). Modeling the Effects of the Natural Environmental and Urban Runoff on Stream Temperature, Final Report. June 22, 2000.

Pluhowski, E.J. (1970) Urbanization and Its Effect on the Temperature of the Streams on Long Island. New York. U.S. Geological Survey Professional Paper 627-D. pp: D1-D59.

Raphael, J.M. (1962) Prediction of Temperature in Rivers and Reservoirs. Journal of the Power Division, Proceedings of the American Society of Civil Engineers, Vol: 88, pp:157-181.

Roa, A. and Norman J.M. 2002. Effects of the Natural Environmental and Urban Runoff on Stream Temperature. (preprint obtained directly from the authors by e-mail)

Roa-Espinosa, A., Norman J.M., Wilson, T. B. and Johnson, K. 2002. Predicting the Impact of Urban Development on Stream Temperature Using TURM (Temperature Urban Runoff Model). (preprint obtained directly from the authors by e-mail) 
Roa-Espinosa, A., Norman J.M., Wilson, T. B. and Johnson, K. September 30, 2003. Temperature Urban Runoff Model (TURM), EXCEL 2000 format (version 1.0 added 8/26/02) <http://www.co.dane.wi.us/landconservation/thmodelpg.htm>

Schroeter, H., D. Van Vliet, K. Boehmer and D. Beach. 1995. "Continuous In-Stream Temperature Modeling: Integration with a Physically- Based Subwatershed Hydrology Model." Journal of Water Management Modeling R191-03. doi: 10.14796/JWMM.R191-03.

Thomann, R.V. and Mueller, J.A. (1987) Principles of Surface Water Quality Modeling and Control. Harper \& Row, Publishers, Inc. pp: 599-600.

Velz, C.J and Gannon, J.J. (1960) Forecasting Heat Loss in Ponds and Streams. Water Pollution Control Federation, Vol: 32. pp: 392-417.

Weatherbe, D.G. 1995. "A Simplified Stream Temperature Model for Evaluating Urban Drainage Inputs." Journal of Water Management Modeling R183-16. doi: 10.14796/JWMM.R183-16.

Xie, D.M. and W. James. 1994. "Modelling Solar Thermal Enrichment of Urban Stormwater." Journal of Water Management Modeling R176-13. doi: 10.14796/JWMM.R176-13. 